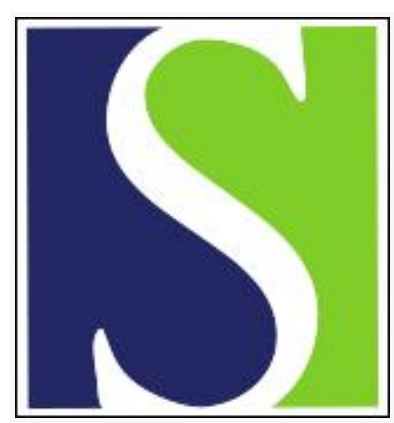

Scand J Work Environ Health 1984;10(3):151-157

https://doi.org/10.5271/sjweh.2348

Issue date: Jun 1984

A mortality study of workers employed in a German rock wool factory.

by Claude J, Frentzel-Beyme R

This article in PubMed: www.ncbi.nlm.nih.gov/pubmed/6474109

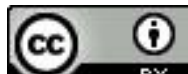




\title{
A mortality study of workers employed in a German rock wool factory
}

\author{
by Jenny Claude, MHS, Rainer Frentzel-Beyme, MD, MHS ${ }^{1}$
}

\begin{abstract}
CLAUDE J, FRENTZEL-BEYME R. A mortality study of workers employed in a German rock wool factory. Scand J Work Environ Health 10 (1984) 151-157. As part of a coordinated European study including 13 plants, 2,096 workers employed in rock wool production, packing, and maintenance activities in a German factory were followed until 1979 for cause-specific mortality. There were no consistent differences between the observed and expected deaths in the study cohort on the basis of the experience of the general population. The separate analysis of persons engaged in rock wool production and packing and those engaged in maintenance yielded an excess of lung cancer deaths with borderline significance for occurrence among the maintenance workers and an elevation in standardized mortality ratio for stomach cancer related to time since first employment in the production group. Comparison with a factory-based reference cohort did not show any increased health risk for the exposed cohort. An extension of the follow-up for five years is planned in an attempt to clarify the present findings.
\end{abstract}

Key terms: epidemiology, follow-up study, internal reference, lung cancer, man-made mineral fibers, mortality, stomach cancer.

Man-made mineral fibers (MMMF) have gained widespread application in recent years due to the need for increased thermal insulation to conserve energy and due to their role as a substitute for asbestos for certain uses.

Such fibers are amorphous silicates made from glass, natural rock, or slag. Although glass fibers differ from asbestos physiochemically and do not split up longitudinally, both man-made mineral fibers and asbestos are fibrous substances. Due to the overwhelming evidence on the pathological and carcinogenic effects from exposure to asbestos, increased research has been directed towards the evaluation of health effects presented by exposure to man-made mineral fibers.

The fibrogenicity and carcinogenicity of manmade mineral fibers have been demonstrated in animal experiments by Stanton \& Wrench (22), Pott et al (16), Davis (5), and Kuschner \& Wright (11), who injected fibrous materials into the pleural and peritoneal cavities and into the trachea. This pathogenicity was found to be related to the structural properties of the injected fibers. Inhalation studies using manmade mineral fibers in the form of dust produced minimal rates of lung cancer $(12,24)$. Different

\footnotetext{
1 Institute of Documentation, Information and Statistics; German Cancer Research Center; Heidelberg; Federal Republic of Germany.
}

Reprint requests to: Ms J Claude; Institute of Documentation, Information and Statistics; German Cancer Research Center; Heidelberg; FRG. authors have quoted particular fiber dimensions found to produce the highest carcinogenic response $(17,21)$, although the relation between biological effectiveness and the geometric characteristics of the fibers (diameter and length) is a continuous one over a large range of values.

Concerning health effects in man, a few case reports can be found in the literature associating diseases of the respiratory tract to exposure to glass fibers (10), but cross-sectional prevalence studies of current employees in the fibrous glass industry have consistently shown negative results $(9,15,23,25)$. The common limitation, however, of prevalenceoriented morbidity studies is that the former employees and the deceased are not accounted for. Results of a retrospective cohort mortality study by Bayliss et al (1) and preliminary findings from a similar study by Enterline \& Marsh (7) suggested an excessive risk only for nonmalignant respiratory diseases, excluding influenza and pneumonia.

In view of the limited evidence on human working populations at the time, the Joint European Medical Research Board invited the International Agency for Research on Cancer (IARC) to carry out an international epidemiologic investigation of the possible health effects of man-made mineral fibers among workers engaged in their production in Europe. For this first international multicentric endeavor, which began in 1978, 13 factories in seven countries were chosen for inclusion in the coordinated study (20). The results of the retrospective follow-up mortality study of a rock wool factory in West Germany are reported in the present communication. 
Table 1. Some characteristics of the exposed and the reference cohorts.

\begin{tabular}{|c|c|c|c|c|c|}
\hline & \multicolumn{2}{|c|}{$\begin{array}{l}\text { Exposed } \\
\text { cohort }\end{array}$} & \multicolumn{2}{|c|}{$\begin{array}{l}\text { Reference } \\
\text { cohort }\end{array}$} & \multirow{2}{*}{$\begin{array}{l}\text { Total } \\
(\mathrm{N})\end{array}$} \\
\hline & $\mathrm{N}$ & $\%$ & $N$ & $\%$ & \\
\hline Number of persons & 2,096 & $\cdot$ & 1,778 & . & 3,874 \\
\hline $\begin{array}{l}\text { Alive } \\
\text { Dead } \\
\text { Lost to }\end{array}$ & $\begin{array}{r}1,655 \\
242\end{array}$ & $\begin{array}{l}79.0 \\
11.5\end{array}$ & $\begin{array}{r}1,372 \\
219\end{array}$ & $\begin{array}{l}77.2 \\
12.3\end{array}$ & $\begin{array}{r}3,027 \\
461\end{array}$ \\
\hline follow-up & 199 & 9.5 & 187 & 10.5 & 386 \\
\hline Number of Germans & 1,842 & 87.9 & 1,596 & 89.8 & 3,438 \\
\hline $\begin{array}{l}\text { Number of migrant } \\
\text { workers }\end{array}$ & 254 & 12.1 & 182 & 10.2 & 436 \\
\hline \multicolumn{6}{|l|}{$\begin{array}{l}\text { Length of } \\
\text { employment }\end{array}$} \\
\hline $\begin{array}{r}<1 \text { year } \\
1-9 \text { years } \\
10-29 \text { years } \\
\geq 30 \text { years }\end{array}$ & $\begin{array}{r}907 \\
671 \\
456 \\
62\end{array}$ & $\begin{array}{r}43.3 \\
32.0 \\
21.7 \\
3.0\end{array}$ & $\begin{array}{r}904 \\
548 \\
274 \\
52\end{array}$ & $\begin{array}{r}50.8 \\
30.8 \\
15.4 \\
2.9\end{array}$ & $\begin{array}{r}1,881 \\
1,149 \\
730 \\
114\end{array}$ \\
\hline $\begin{array}{l}\text { Person-years } \\
\text { at risk }\end{array}$ & 33,755 & & 29,118 & . & 62,873 \\
\hline
\end{tabular}

Table 2. Mortality analysis by time since first employment for the exposed cohort of production and maintenance work. ers. $(S M R=$ standardized mortality ratio, $C L=$ confidence limits, $I C D=$ International Classification of Diseases and Causes of Death, eighth revision)

\begin{tabular}{|c|c|c|c|c|}
\hline \multirow{2}{*}{$\begin{array}{l}\text { Time since first } \\
\text { employment } \\
\text { (years) }\end{array}$} & \multicolumn{2}{|c|}{ Deaths } & \multirow[b]{2}{*}{ SMR } & \multirow[b]{2}{*}{$\mathrm{CL}$} \\
\hline & $\begin{array}{c}\text { Ob- } \\
\text { served }\end{array}$ & $\begin{array}{c}\text { Ex- } \\
\text { pected }\end{array}$ & & \\
\hline
\end{tabular}

\section{All causes (ICD 000-999)}

$\begin{array}{crrrr}\leq 9 & 53 & 56.1 & 94 & 72-123 \\ 10-19 & 83 & 85.9 & 97 & 77-120 \\ 20-29 & 86 & 74.4 & 116 & 92-143 \\ \geq 30 & 20 & 18.3 & 109 & 68-166 \\ \text { Total } & 242 & 234.7 & 103 & 91-117\end{array}$

Malignant neoplasms (ICD 140-209)

$\begin{array}{crrrr}\leq 9 & 6 & 9.3 & 64 & 26-134 \\ 10-19 & 19 & 18.8 & 101 & 63-156 \\ 20-29 & 27 & 17.5 & 154^{*} & 104-221 \\ \geq 30 & 6 & 4.2 & 144 & 57-297 \\ \text { Total } & 58 & 49.8 & 116 & 88-151\end{array}$

Stomach cancer (ICD 151)

$$
\begin{array}{r}
\leq 9 \\
10-19 \\
20-29 \\
\geq 30
\end{array}
$$

Total

$\begin{array}{rr}0 & 1.5 \\ 5 & 3.2 \\ 6 & 2.8 \\ 0 & 0.8 \\ 11 & 8.3\end{array}$

\section{Material and methods}

The factory selected for this study produced rock wool by a steam-blowing process from 1942 until 1977 when this branch of the company was closed down. Owing to this fact, an environmental survey of the plant was not feasible.

All persons eligible for inclusion in the exposed cohort were ascertained through the available company payroll records; they comprised all those employed in rock wool production, packing, shipping, and maintenance activities some time between 1942 and 1977 , classified according to the main occupation. No restrictions were made on minimal duration of employment.

A reference cohort was selected in a similar manner from workers in cork and styropor panel production of the same company. The exposed and reference cohorts were subsequently limited to male employees, consisting then of 2,096 males in the former and 1,778 males in the latter group.

Table 3. Mortality analysis by time since first employment for the subcohort of production workers. $(S M R=$ standard ized mortality ratio, $\mathrm{CL}=$ confidence limits, $\mathrm{CD}=$ International Classification of Diseases and Causes of Death, eighth revision)

\begin{tabular}{lcccc}
\hline \multirow{2}{*}{$\begin{array}{l}\text { Time since first } \\
\text { employment } \\
\text { (years) }\end{array}$} & \multicolumn{2}{c}{ Deaths } & & \\
\cline { 2 - 2 } & $\begin{array}{c}\text { Ob- } \\
\text { served }\end{array}$ & $\begin{array}{c}\text { Ex- } \\
\text { pected }\end{array}$ & SMR & $C L$ \\
\hline
\end{tabular}

All causes (ICD 000-999)

$\begin{array}{crrrr}\leq 9 & 36 & 36.1 & 100 & 71-137 \\ 10-19 & 46 & 55.0 & 84 & 62-111 \\ 20-29 & 49 & 49.1 & 100 & 75-131 \\ \geq 30 & 12 & 12.0 & 100 & 57-176 \\ \text { Total } & 143 & 152.1 & 94 & 79-111\end{array}$

Malignant neoplasms (ICD 140-209)

$\begin{array}{crrrr}\leq 9 & 4 & 6.0 & 66 & 21-161 \\ 10-19 & 10 & 12.0 & 83 & 42-149 \\ 20-29 & 17 & 11.6 & 147 & 88-230 \\ \geq 30 & 5 & 2.6 & 189 & 71-426 \\ \text { Total } & 36 & 32.2 & 112 & 78-155\end{array}$

Stomach cancer (ICD 151)

$\begin{array}{ccccc}\leq 9 & 0 & 0.9 & - & - \\ 10-19 & 3 & 2.1 & 144 & 36-389 \\ 20-29 & 5 & 1.8 & 273^{*} & 102-616 \\ \geq 30 & 0 & 0.5 & - & - \\ \text { Total } & 8 & 5.4 & 147 & 69-281\end{array}$

Lung cancer (ICD 162)

Lung cancer (ICD 162)

$\begin{array}{crrrr}\leq 9 & 2 & 2.1 & 97 & 16-315 \\ 10-19 & 7 & 5.2 & 134 & 59-266 \\ 20-29 & 5 & 5.1 & 98 & 36-217 \\ \geq 30 & 2 & 1.1 & 176 & 31-601 \\ \text { Total } & 16 & 13.5 & 118 & 70-188\end{array}$

Diseases of the respiratory system (ICD 460-519)

\begin{tabular}{crrrr}
$\leq 9$ & 1 & 2.3 & 44 & $2-2 \uparrow 4$ \\
$10-19$ & 4 & 4.8 & 83 & $27-201$ \\
$20-29$ & 4 & 5.2 & 77 & $24-186$ \\
$\geq 30$ & 2 & 1.6 & 127 & $21-413$ \\
iotal & 11 & 13.9 & 79 & $42-138$ \\
\hline
\end{tabular}

$* p<0.05$. $\leq 9$

$10-19$

$20-29$

$\geq 30$

Total

Diseases of the respiratory system (ICD 460-519)

\begin{tabular}{crrrr}
$\leq 9$ & 1 & 1.5 & 68 & $3-329$ \\
$10-19$ & 4 & 3.1 & 131 & $41-311$ \\
$20-29$ & 4 & 3.4 & 118 & $37-284$ \\
$\geq 30$ & 1 & 1.1 & 95 & $5-448$ \\
Total & 10 & 9.0 & 112 & $56-198$ \\
\hline
\end{tabular}

$\star p<0.05$. 
In an effort to ascertain the vital status until 31 December 1979, follow-up of all cohort members was attempted through multiple contacts and inquiries at the registrar's offices of a worker's last residence or at his birthplace. Death certificates were requested from the government health offices of each place of death.

The ascertainment of the cause of death was impeded by the increasingly stringent interpretation of the "Datenschutzgesetzgebung" (legislation on data protection) and by the fact that, in some municipalities, the death certificates are only kept for 5 or 10 years. Nevertheless, death certificates were obtained for $93 \%$ of those known to be dead.

The underlying cause of death was coded by a qualified coder according to the eighth revision of the International Classification of Diseases and Causes of Death.

Analysis of the study data was carried out with the help of computer programs prepared at the German Cancer Research Center $(2,3)$.

A modified life-table technique was used to obtain person-years at risk of dying beginning at the first date of employment or on 1 January 1942, whichever came later. Individuals with unknown vital status contributed to person-years at risk until the date of last information. The deceased for whom no death certificates were available were assumed to have died from an unknown cause.

For the external comparison, person-years at risk were calculated by five-year age groups, five-year calendar time periods, number of years since first employment (latency), and duration of exposure. The observed numbers of deaths were compared to those expected on the basis of age-calendar time and causespecific mortality rates for the general male population of West Germany. Standardized mortality ratios (SMR) between observed deaths and the expected ones multiplied by 100 were calculated, and exact $95 \%$ confidence limits (CL) were computed (19). ${ }^{2}$

In addition, an internal comparison with the reference cohort was carried out by 10-year age groups and latency. A weighted average of the stratumspecific rate ratios, proposed by Rothman \& Boice (19), was employed for the estimation of the relative risk (RR) in preference to Miettinen's rate ratio estimate (13) due to the presence of strata with zero or small numbers.

Ninety-five percent test-based confidence limits were calculated from the point estimate with the use of the standard normal deviate (13). The hypothesis testing of the data was achieved through the calculation of p-values (19).

\footnotetext{
2 In a previous report on this study, person-years were calculated starting from 1946 and standardized mortality ratios were calculated with reference to regional mortality rates (from the Federal State of Rhineland-Palatinate), so results are not comparable (4).
}

\section{Results}

\section{General characteristics}

There was no apparent difference in the general characteristics of the exposed and reference cohorts (table 1). The inclusion of migrant workers led to a rather conservative estimate of the standardized mortality ratio when it is considered that they represent $62 \%$ of the persons who were lost to follow-up.

The mean duration of employment was 6.2 (median 1.6) years for the exposed cohort and 4.9 (median 0.9) years for the reference cohort; $43.3 \%$ of the exposed cohort and $50.8 \%$ of the reference cohort were employed for less than one year and only $3 \%$ for $\geq 30$ years.

\section{External comparison}

For the exposed cohort, as well as the subcohorts of production workers and maintenance workers; tables 2-4 show the observed and expected numbers of

Table 4. Mortality analysis by time since first employment for the subcohort of maintenance workers. (SMR $=$ standardized mortality ratio, $C L=$ confidence limits, $I C D=I n$ ternational Classification of Diseases and Causes of Death, eighth revision)

\begin{tabular}{lcccc}
\hline Time since first & \multicolumn{2}{c}{ Deaths } & \\
\cline { 2 - 2 } $\begin{array}{l}\text { employment } \\
\text { (years) }\end{array}$ & $\begin{array}{c}\text { Ob- } \\
\text { served }\end{array}$ & $\begin{array}{c}\text { Ex- } \\
\text { pected }\end{array}$ & SMR & $C L$ \\
\hline
\end{tabular}

All causes (ICD 000-999)

$\begin{array}{crrrrr}\leq 9 & 17 & 20.0 & 85 & 51- & 133 \\ 10-19 & 37 & 30.9 & 120 & 86- & 163 \\ 20-29 & 37 & 25.3 & 146^{\star} & 106- & 200 \\ \geq 30 & 8 & 6.3 & 126 & 59- & 241 \\ \text { Total } & 99 & 82.5 & 120 & 98- & 146\end{array}$

Malignant neoplasms (ICD I40-209)

$\begin{array}{crrrrr}\leq 9 & 2 & 3.3 & 60 & 10- & 200 \\ 10-19 & 9 & 6.8 & 133 & 65- & 243 \\ 20-29 & 10 & 6.0 & 167 & 85- & 297 \\ \geq 30 & 1 & 1.5 & 66 & 3- & 329 \\ \text { Total } & 22 & 17.6 & 125 & 80- & 186\end{array}$

Stomach cancer (ICD I5I)

$\begin{array}{cccccc}\leq 9 & 0 & 0.6 & - & - & \\ 10-19 & 2 & 1.1 & 174 & 31- & 601 \\ 20-29 & 1 & 0.9 & 107 & 6- & 548 \\ \geq 30 & 0 & 0.3 & - & - & \\ \text { Total } & 3 & 2.9 & 104 & 26- & 282\end{array}$

Lung cancer (ICD 162)

$\begin{array}{cllll}\leq 9 & 1 & 0.8 & 133 & 6-617 \\ 10-19 & 3 & 1.9 & 156 & 40-430 \\ 20-29 & 4 & 1.8 & 228 & 71-536 \\ \geq 30 & 1 & 0.4 & 228 & 13-1,233 \\ \text { Total } & 9 & 4.9 & 185 & 90-337\end{array}$

Diseases of the respiratory system (ICD 460-519)

\begin{tabular}{|c|c|c|c|c|c|}
\hline $\begin{array}{r}\leq 9 \\
10-19 \\
20-29 \\
\geq 30\end{array}$ & $\begin{array}{l}0 \\
0 \\
0 \\
1\end{array}$ & $\begin{array}{l}0.8 \\
1.7 \\
1.9 \\
0.5\end{array}$ & $\frac{\overline{-}}{\overline{193}}$ & $\begin{array}{r}- \\
10-\end{array}$ & 986 \\
\hline Total & 1 & 4.9 & 20 & $1-$ & 101 \\
\hline
\end{tabular}

* $p<0.05$. 
deaths for five selected groups of causes of death and the standardized mortality ratios with the $95 \%$ confidence limits. No significantly increased mortality was found for any of the groups of causes for the entire period of observation. The analysis of the exposed cohort by time since first employment showed neither increased mortality with time nor standardized mortality ratios with a significant departure from 100 for all causes or diseases of the respiratory system. The standardized mortality ratio for malignant neoplasms tended to increase with time since first employment and attained a statistically significant excess in the group 20-29 years since first employment $(\mathrm{SMR}=154, \mathrm{CL}=104-221)$. The standardized mortality ratios for stomach cancer were high although deaths occurred in only two time periods, $10-19$ years and $20-29$ years since first employment. In the latter time period there were 6 observed deaths versus 2.8 expected ones. There was a slight tendency towards higher mortality for lung cancer, but the findings were not significant, the highest standardized mortality ratio being observed for the group $\geq 30$ years since first employment.

The separate analysis of the subcohorts of production workers and of maintenance workers revealed discernible differences in the mortality from stomach cancer and from lung cancer. The standardized mortality ratio for stomach cancer among the production workers reached statistical significance with $20-29$ years since first employment $(\mathrm{SMR}=273, \mathrm{CL}=$ 102-616), whereas mortality remained insignificant for the maintenance workers. On the other hand, mortality from lung cancer among the maintenance workers increased steadily with time since first em- ployment, and all the standardized mortality ratios exceeded 100 . For the total period of observation the standardized mortality ratio was $185(\mathrm{CL}=90-337)$.

The standardized mortality ratios were also calculated for the reference group. They showed statistical significance only for all causes for the groups $10-19$ years $(S M R=126, C L=103-154)$ and $\geq 30$ years $(S M R=170, C L=105-260)$ since first $\mathrm{em}$ ployment but not for any of the other groups of causes examined.

The analysis by duration of exposure for the exposed cohort revealed a discernible trend of increase in the standardized mortality ratios with increasing duration of exposure only for stomach cancer, but they were not statistically significant.

\section{Internal comparison}

In the attempt to remove some of the potential sources of noncomparability of an occupational cohort with respect to the general population, relative risks were calculated for the exposed versus the reference cohort for selected causes of death or groups of causes for the entire period of observation (table 5). Despite cause-specific excesses and deficits, there was no statistically significant departure from 1.00 in the relative risks except for neoplasms of unspecified nature $(R R=7.03, \quad C L=1.17-42.3)$. In this group only one death was observed in the reference cohort, whereas in the exposed cohort there were eight deaths of which six were tumors located in the brain. A larger number of neoplasms of unspecified sites was also found for the exposed cohort, but the relative risk was not statistically significant. For

Table 5. Cause-specific deaths among the exposed and the reference cohorts and the relative risks for the total period of observation.

\begin{tabular}{|c|c|c|c|c|}
\hline \multirow{2}{*}{ Cause of death ${ }^{a}$} & \multicolumn{2}{|c|}{ Number of deaths } & \multirow{2}{*}{$\begin{array}{l}\text { Relative } \\
\text { risk }\end{array}$} & \multirow{2}{*}{$\begin{array}{l}\text { Confidence } \\
\text { limits }\end{array}$} \\
\hline & Study cohort & Reference cohort & & \\
\hline All causes $(000-999)$ & 242 & 219 & 0.91 & $0.76-1.10$ \\
\hline Malignant neoplasms $(140-209)$ & 58 & 44 & 1.09 & $0.74-1.61$ \\
\hline Esophagus (150) & 2 & 0 & - & - \\
\hline Stomach (151) & 11 & 9 & 1.06 & $0.44-2.54$ \\
\hline Intestine except rectum $(152,153)$ & 3 & 2 & 1.30 & $0.21-7.92$ \\
\hline Rectum (154) & 2 & 5 & 0.31 & $0.07-1.31$ \\
\hline Liver (155) & 2 & 1 & 1.45 & $0.12-17.54$ \\
\hline Pancreas (157) & 5 & 0 & - & - \\
\hline Larynx (161) & 2 & 2 & 0.85 & $0.12-6.05$ \\
\hline Bronchus and lung (162) & 16 & 11 & 1.23 & $0.5 \overline{7}-2.68$ \\
\hline Mesothelioma (163) & 0 & 1 & $\overline{27}$ & - \\
\hline Prostate (185) & 2 & 3 & 0.37 & $0.06-2.44$ \\
\hline Unspecified sites (195-199) & 8 & 3 & 2.20 & $0.60-8.17$ \\
\hline Others $(172,189-193)$ & 3 & 4 & - & - \\
\hline Leukemia and Iymphatic system (200-207) & 2 & 3 & 0.57 & $0.10-3.37$ \\
\hline Neoplasms of unspecified nature $(230-239)$ & 8 & 1 & $7.03^{\star}$ & $1.17-42.29$ \\
\hline Circulatory system $(390-458)$ & 70 & 80 & 0.70 & $0.51-0.97$ \\
\hline Respiratory system $(460-519)$ & 11 & 9 & 1.00 & - \\
\hline Influenza, pneumonia (470-486) & 6 & 5 & 1.04 & $0.32-3.37$ \\
\hline Others $(460-466,490-519)$ & 5 & 4 & 0.95 & $0.24-3.75$ \\
\hline Digestive system $(520-577)$ & 17 & 23 & 0.60 & $0.32-1.13$ \\
\hline Accidents, poisonings, violence $(800-999)$ & 42 & 32 & 1.12 & $0.71-1.77$ \\
\hline
\end{tabular}

a The numbers of the International Classification of Diseases and Causes of Death, eighth revision, are in parentheses. * $p<0.05$. 
pancreas cancer, for which five versus no deaths were observed, the $p$-value was significant $(p<0.05)$.

Relative risks by time since first employment were also performed for the five groups of causes of death of particular interest. The point estimates of the relative risk tended to decrease in the first 10 years after first employment and then increase slightly up to 30 years since first employment although not a single relative risk estimate was statistically significantly increased. The number of person-years at risk for the period $\geq 30$ years since first employment may be too small to give a reliable estimate of the relative risk.

\section{Discussion}

The results of this study showed no significantly increased risk for any cause of death among persons engaged in rock wool production, packing, and maintenance activities with reference to the mortality of the general population.

A separate analysis of persons engaged in rock wool production and packing and those engaged in maintenance activities was performed in order to account for the presumed difference in the intensity of exposure. An excess of lung cancer deaths with borderline statistical significance was found among the maintenance workers (SMR $=185, \mathrm{CL}=90-337)$. For the production workers, elevated standardized mortality ratios were observed for stomach cancer, weakly related to duration of exposure, as well as with the time since first employment, although no deaths were observed after 30 years since first employment.

Also the analysis with reference to persons engaged in other production processes did not reveal any other risks. An unusual finding was an excess of neoplasms of unspecified nature, in particular that of the brain. Four of the six cases of tumors of the brain turned out to have been employed for only one year or less, the causal role of man-made mineral fiber exposure therefore being less probable.

The main objective of this study was to investigate whether exposure to respirable man-made mineral fibers induces malignant and nonmalignant respiratory diseases. Unfortunately, measurements on the level of respirable fibers in the production environment were not available.

The interpretation of positive findings may be complicated by the possibility of exposure to asbestos used for manufacturing certain other products within the company premises. Interestingly though, no single case of mesothelioma was found in the exposed cohort, whereas one death from mesothelioma occurred in the reference cohort. The presence of other substances in the environment of the workers, including silica, formaldehyde, oil binders, and coal tar, constitutes a further complication in the identification of the health effects associated with exposure to man-made mineral fibers. In particular, for persons engaged in maintenance activities and not necessarily confined to the man-made mineral fiber production, a mixed exposure was unavoidable. Neither was there any information available on previous occupational history and tobacco smoking habits.

In addition, the majority of the workers were employed (thus exposed) for a short period of time (43\% were employed for less than one year), and only a few hundred person-years occurred for the group exposed $\geq 30$ years after first employment.

On the other hand, due to the missing information on causes for $7 \%$ of the deaths and the uncertainty of location for many of the neoplasms of unspecified sites, our standardized mortality ratios for specific causes of death may be underestimated.

Thus the evidence from this study indicates some adverse health effects from the production environment which cannot be causally related to man-made mineral fiber exposure.

The results of our study are not directly comparable to those presented for the coordinated European Study (20) since in their evaluation person-years and expected values were computed starting from the first year in which the national reference rates were available (for West Germany, 1952). Moreover, period of observation was accounted for since actual first employment in the company, whereas this study used time since the beginning of the man-made mineral fiber production (1942) for persons who entered the company earlier.

With regard to lung cancer mortality, the results of our study are consistent with the findings of other investigators reported at the Conference on the Biological Effects of Man-Made Mineral Fibres in Copenhagen, April 1982, which did not confirm an increased risk of lung cancer $(6,8,14,20)$. On the other hand, Enterline \& Marsh (8) observed an excess of deaths from nonmalignant respiratory diseases but could not support a causal role for man-made mineral fibers because the standardized mortality ratios by duration of employment and by time since onset of employment did not show any trend. Moreover, asbestos may have been used in some of the plants. They also found a slightly elevated standardized mortality ratio for digestive cancer. An increase in deaths due to digestive cancer and nonmalignant respiratory diseases was also observed in another study of workers in a plant producing mineral wool (18).

Thus it is interesting that an increase of stomach cancer deaths among persons engaged in production and packing has been found in our study.

Although the evidence does not seem to confirm adverse health effects from respirable man-made mineral fibers inhaled in a normal work environment, the excess of deaths from lung cancer, digestive cancer, and nonmalignant respiratory diseases observed in several studies, including our own, even though not always statistically significant, warrant 
further investigation. As a consequence, continuing efforts are being considered to follow-up the cohort for another five years in order to increase the size of the essential part of the cohort, namely, those ob- . served for $\geq 30$ years.

\section{Acknowledgments}

The authors wish to thank Ms U Klappauf, Ms M Hochlehnert, and Dr N Becker for their cooperation in this study. Special mention should be made of Ms $U$ Eilber for her sustained efforts in the preparation of the data and to Mr H-J Stenger for his dedicated assistance in the preparation of the computer programs. The coding, carried out by the Statistical Office Bad Ems, is greatly appreciated.

This investigation was carried out under a collaborative research agreement with the International Agency for Research on Cancer (IARC) Lyon, France.

\section{References}

1. Bayliss DL, Dement JM, Wagoner JK, Blejer HP. Mortality patterns among fibrous glass production workers. Ann NY Acad Sci 271 (1976) 324-335.

2. Becker N, Stenger HJ. MONITOR - Ein Programmpaket zur Auswertung von Mortalitätsdaten. Deutsches Krebsforschungszentrum, Abteilung Epidemiologie, Heidelberg 1979. (Technical Report Nr 1).

3. Becker N, Stenger HJ. EPAS - Epidemiologisches Auswertungssystem. Deutsches Krebsforschungszentrum, Abteilung Epidemiologie, Heidelberg 1980. (Technical Report Nr 2).

4. Claude J. Follow-up Studie zur Krebsgefährdung bei Exposition gegenüber künstlichen Mineralfasern. In: Berger J, Höhne KH, ed. Methoden der Statistik und Informatik in Epidemiologie und Diagnostik. 27. Jahrestagung der GMDS, Hamburg, 27.-29. September 1982, Proceedings. Springer-Verlag, Berlin Heidelberg 1983, pp 25-37.

5. Davis JMG. Pathological aspects of the injection of glass fiber into the pleural and peritoneal cavities of rats and mice. In: Occupational exposure to fibrous glass: Proceedings of a symposium, College Park, Maryland, June 26-27, 1974. US Department of Health, Education and Welfare, Washington, DC 1976, pp 141-149. [HEW publications no (NIOSH) 76-151].

6. Englund A, Engholm G, Hallin N, v Schmalensee G. Respiratory cancer in Swedish construction workers exposed to MMMF. In: Biological effects of manmade mineral fibres: Report on a WHO/IARC meeting, Copenhagen, 20-22 April 1982. World Health Organization, Copenhagen 1983, p 90. (EURO reports and studies 81 ).

7. Enterline PE, Marsh GM. Mortality of workers in the man-made mineral fiber industry. In: Wagner JC, ed. Biological effects of mineral fibres. Volume 2. International Agency for Research on Cancer, Lyon 1980, pp 965-972. (IARC scientific publication no 30).

8. Enterline PE, Marsh GM. Mortality of workers in the MMMF industry. In: Biological effects of man-made mineral fibres: Report on a WHO/IARC meeting, Copenhagen, 20-22 April 1982. World Health Organization, Copenhagen 1983, pp 84-85. (EURO reports and studies 81 ).
9. Gross P, Harley RA, Davis JMG. The lungs of fiber glass workers: Comparison with the lungs of a control population. In: Occupational exposure to fibrous glass: Proceedings of a symposium, College Park, Maryland, June 26-27, 1974. US Department of Health, Education and Welfare, Washington, DC 1976, pp 249-263. (HEW publications no (NIOSH) 76-151).

10. Hill JW. Health aspects of man-made mineral fibres: A review. Ann Occup Hyg 20 (1977) 161-173.

11. Kuschner $M$, Wright $G$. The effects of intratracheal instillation of glass fiber of varying sizes in guinea pigs. In: Occupational exposure to fibrous glass: Proceedings of a symposium, College Park, Maryland, June 26-27, 1974. US Department of Health, Education and Welfare, Washington, DC 1976, pp 151-168. (HEW publications no (NIOSH) 76-151).

12. McConnell EE, Wagner JC, Skidmore JW, Moore JA. Two inhalation studies: A comparison. In: Biological effects of man-made mineral fibres: Report on a WHO/IARC meeting, Copenhagen, 20-22 April 1982. World Health Organization, Copenhagen 1983, pp 118-120. (EURO reports and studies 81).

13. Miettinen OS. Estimability and estimation in casereferent studies. Am J Epidemiol 103 (1976) 226-235.

14. Morgan RW, Kaplan SD, Bratsberg JA. Mortality among fibrous glass production workers. In: Biological effects of man-made mineral fibres: Report on a WHO/IARC meeting, Copenhagen, 20-22 April 1982. World Health Organization, Copenhagen 1983, pp $86-87$. (EURO reports and studies 81 ).

15. Nasr AN, Ditchek T, Scholtens PA. The prevalence of radiographic abnormalities in the chest of fiber glass workers. J Occup Med 13 (1971) 371-376.

16. Pott F, Friedrichs KH. Tumoren der Ratte nach i.p.Injektion faserförmiger Stäube. Naturwissenschaften 59 (1972) 318

17. Pott F, Friedrichs KH, Huth F. Ergebnisse aus Tierversuchen zur kanzerogenen Wirkung faserförmiger Stäube und ihre Deutung im Hinblick auf die Tumorentstehung beim Menschen. Zbl Bakt Hyg I Abt Orig B 162 (1976) 467-505.

18. Robinson CF, Dement JM, Ness GO, Waxweiler RJ. Mortality patterns of rock and slag mineral wool production workers: An epidemiological and environmental study. Br J Ind Med 39 (1982) 45-53.

19. Rothman KJ, Boice JD Jr. Epidemiologic analysis with a programmable calculator. US Government Printing Office, Washington, DC 1979. (NIH pub no 79-1649).

20. Saracci R, Simonato L, Acheson ED, Andersen A, Bertazzi PA, Claude J, Charnay N, Estève J, FrentzelBeyme RR, Gardner MJ, Jensen O, Maasing R, Olsen J, Teppo L, Westerholm P, Zocchetti C. The IARC mortality and cancer incidence study of MMMF production workers. In: Biological effects of man-made mineral fibres: Report on a WHO/IARC meeting, Copenhagen, 20-22 April 1982. World Health Organization, Copenhagen 1983, pp 80-83. (EURO reports and studies 81).

21. Stanton MF, Layard M, Tegeris A, Miller E, May M, Kent E. Carcinogenicity of fibrous glass: Pleural response in the rat in relation to fiber dimension. $\mathrm{J}$ Natl Cancer Inst 58 (1977) 587-603.

22. Stanton MF, Wrench C. Mechanisms of mesothelioma induction with asbestos and fibrous glass. J Natl Cancer Inst 48 (1972) $797-817$.

23. Utidjian $\mathbf{M}$, Cooper WC. Human epidemiologic studies with emphasis on chronic pulmonary effects. In: Occupational exposure to fibrous glass. Proceedings of a symposium, College Park, Maryland, June 26-27, 1974. US Department of Health, Education and Welfare, Washington, DC 1976, pp 223-224. (HEW publications no (NIOSH) 76-151). 
24. Wagner JC. Effects of inhalation and intrapleural inoculation of rats. In: Biological effects of man-made mineral fibres: Report on a WHO/IARC meeting, Copenhagen, 20-22 April 1982. World Health Organization, Copenhagen 1983, p 117. (EURO reports and studies 81).

25. Wright GW. Airborne fibrous glass particles: Chest roentgenograms of persons with prolonged exposure. Arch Environ Health 16 (1968) 175-181.

Received for publication: 24 August 1983 